Cite as: Huijibers CM, Schlacher TA, Schoeman DS, Westone MA, Connolly RM (2013)

Urbanisation alters processing of marine carrion on sandy beaches. Landscape and Urban Planning 119:1-8

\title{
Urbanisation alters processing of marine carrion on sandy beaches
}

\author{
Chantal M. Huijbers ${ }^{1,2, *}$, Thomas A. Schlacher ${ }^{2}$, Dave S. Schoeman², Michael A. Weston ${ }^{3}$, Rod M. \\ Connolly ${ }^{1}$ \\ Australian Rivers Institute - Coast \& Estuaries, and School of Environment, Griffith University, Gold \\ Coast, Qld 4222, Australia \\ ${ }^{2}$ Faculty of Science, University of the Sunshine Coast, Maroochydore DC, Qld 4558, Australia \\ ${ }^{3}$ Deakin University, Centre for Integrative Ecology, School of Life and Environmental Sciences, Deakin \\ University, Burwood, 3125, Australia.
}

*Corresponding author:

Phone: +61-7-55529189

E-mail: c.huijbers@griffith.edu.au

\section{Highlights}

- Coastal urbanisation significantly alters the composition of scavengers at the land-ocean interface

- Invasive mammals replace iconic raptors as scavengers on urban sandy beaches

- Raptors rapidly remove marine carrion from rural beaches

- Differences in scavenger community structure associated with land-use change may have profound effects on key ecological processes

\begin{abstract}
Sandy shores are highly attractive for urban development. Urbanisation of beaches is, however, not without environmental consequences, but metrics of ecological change along metropolitan coasts are poorly developed; this lack of metrics impedes environmentally-effective coastal zone management. Here we test the effects of urbanisation on a pivotal ecological process on sandy shorelines: carrion removal by vertebrate scavengers. Scavenging is a key process linking ocean and land ecosystems via animal carcasses deposited on beaches and subsequently consumed by mostly terrestrial animals. In this study, experimentally placed fish carcasses were monitored with motion-triggered cameras on urban and rural beaches on the east coast of Australia. Urbanisation substantially influenced the structure of the scavenger guild and the frequency of carrion removal within 24 hours. Large raptors were abundant on rural beaches where they rapidly detected and consumed carrion ( $98 \%$ of carcasses removed within $24 \mathrm{~h}$ ). We detected no scavenging activity of raptors on urban beaches where scavenging birds of prey were functionally replaced by nocturnally-foraging, non-native mammals (red fox, Vulpes vulpes), or feral species (cats, dogs) known to threaten beach-dwelling wildlife. Our findings emphasize the value of nonurbanised coastal dunes and sandy beaches as important feeding sites and habitats for iconic and threatened raptors. We also show that human changes in coastal land-use profoundly alter ecological structures and processes on sandy shorelines, aspects that warrant explicit inclusion in landscape management and planning of the coastal strip.
\end{abstract}




\section{Introduction}

Coastal cities are hotspots of environmental change, driven by the continual expansion of the urban footprint in a narrow strip of land bordering the oceans (Martínez et al., 2007). This growth of coastal urbanisation has serious environmental consequences, such as the loss and fragmentation of habitats, overexploitation of fish stocks, pollution, and depletion of populations of coastal species (Lotze et al., 2006; Schlacher and Thompson, 2012). Environmental management of the growing urban footprint in coastal areas is a formidable challenge, chiefly because the main objectives of protecting infrastructure and maximising amenity values often dominate the agenda at the cost of environmental conservation (Duxbury and Dickinson, 2007; Schlacher et al., 2007; Schlacher et al., 2006).
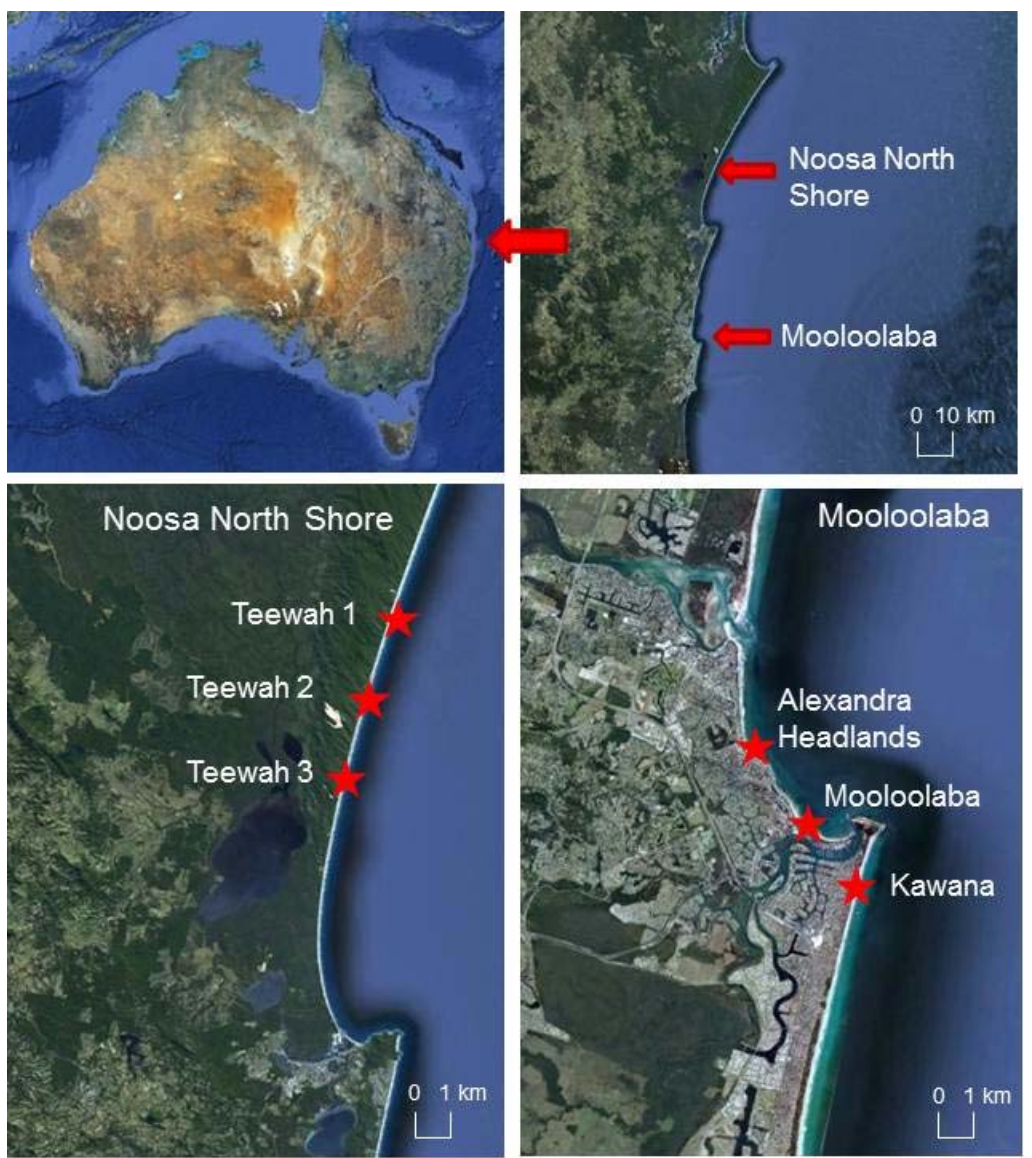

Figure 1. A: Location of the study area in Eastern Australia, with B) exact locations of three sections of beach along the rural Noosa North Shore (left panel), and three urban beaches in the vicinity of the town of Mooloolaba (right panel).

Sandy beaches geographically dominate coastlines around the world, and much of the coastal urban development occurs behind sandy beaches (Gurran, 2008; Noriega et al., 2012). Beaches are the longest ecological interface between the oceans and the land, forming hotspots of bio- 
geochemical processing of material (Schlacher et al., 2008). Almost all of the material processed in beach ecosystems is imported from the sea, making beaches prime examples of 'subsidised' food webs (Polis and Hurd, 1996). Carrion (animal carcasses, usually washed ashore) is a distinct source of marine subsidy to beaches, and a diverse suite of scavengers utilise this resource (McLachlan and Brown, 2006). Scavengers on beaches tend to be facultative rather than obligate scavengers, and are little studied (Beasley et al., 2012).

Scavenging, on beaches and elsewhere, is a key ecological process (Barton et al., 2013). Numerous factors (e.g. carrion availability, predictability, quality) influence the diversity and type of scavengers, and the rate at which carrion is processed (DeVault et al., 2003). Notwithstanding this variability, scavenging is seen as a pivotal pathway of energy transfer in most food webs (Wilson and Wolkovich, 2011). Previously, most research has focused on scavenging communities in undisturbed habitats (e.g. Ogada et al., 2012; Parmenter and MacMahon, 2009; Selva et al., 2005), with only a few studies addressing this important ecological process in ecosystems affected by human impacts (DeVault et al., 2011). Because sandy beaches are systems that are underpinned energetically by imports of organic matter (overwhelmingly from the sea), scavenging is predicted to be a key functional element of beach systems (Rose and Polis, 1998; Schlacher et al., 2013), yet how this process is influenced by urbanisation of sandy beaches is unknown.

We used a field experiment to assess the effects of coastal urbanisation on scavengers and necromass consumption on sandy beaches. Urbanisation globally causes biotic homogenisation, often at the cost of native species (McKinney, 2006), and thus is predicted to alter the species richness and composition of scavenger guilds on urban beaches. We specifically tested if: a) the species composition of the scavenger guild at beaches and dunes differs between urban and rural areas, and b) whether such structural changes have consequences for the short-term scavenging efficiency (i.e. carcass removal within $24 \mathrm{~h}$ ) of carrion from the shoreline.

\section{Methods}

\subsection{Study area}

This study was conducted on the Sunshine Coast in southeast Queensland, Australia (Figure 1A). This area is one of the fastest-growing coastal regions in Australia (Australian Bureau of Statistics 2012), and is intensively used for beach recreation. Areas of intense coastal urbanisation, such as the town of Mooloolaba, are interspersed with rural coastal areas, such as those found to the north of the Noosa River Estuary (Figure 1B). We use the term 'rural' as defined by the Australian Bureau of Statistics as being non-urban, having extremely low levels of human habitation and generally natural vegetation.

The coastline of Mooloolaba has been significantly transformed over the past century by urban development, where infrastructure (e.g. boardwalks, seawalls, playgrounds, roads, buildings, etc.) 
have largely replaced natural ecosystems. This has reduced dune width, and completely eliminated dunes in some places (Longhurst, 1997; Lucrezi et al., 2009). By contrast, beaches and dunes north of the Noosa Estuary are located within the Great Sandy National Park; infrastructure is minimal and the $50 \mathrm{~km}$ of continuous beach is backed by extensive dunes.

\subsection{Experiments}

We measured species composition of the scavenging guild and short-term carcass removal rates on three urban and three rural beaches (Fig. 1). The urban beaches were centred on the town of Mooloolaba (Kawana Beach, Mooloolaba Beach, and Alexandra Headland; $26.40^{\circ} \mathrm{S}, 153.07^{\circ} \mathrm{E}$ ), while the rural beach sections where located on the Noosa North Shore $\left(26.15^{\circ} \mathrm{S}, 153.05^{\circ} \mathrm{E}\right)$.

In our experimental design, 'Urbanisation' represents a fixed factor with two levels: urban and rural. 'Beach' is a random factor with six levels, nested within 'Urbanisation'. Each beach contained four replicate sites for experimental observations. The distance between beaches, within treatments, was $\sim 2 \mathrm{~km}$, while replicate sites within beaches were spaced $\sim 200 \mathrm{~m}$ apart along the shore. The experiment was repeated five times over a six-week period in June - August 2012, adding a final random effect ('Trial') to our design. The average minimum and maximum temperatures ( \pm s.d.) for the five days on which sampling occurred were $8.0( \pm 3.6){ }^{\circ} \mathrm{C}$ and 21.3 $( \pm 1.9)^{\circ} \mathrm{C}$, respectively (data from Bureau of Meteorology, Australia). In each trial, carrion was deployed at the same sites. In total, we conducted 120 camera deployments, but retrieved results from only 114 cameras due to theft or interference $(n=59$ for rural beaches, $n=55$ for urban beaches). Due to logistical constraints, trials on urban and rural beaches were conducted on separate, but consecutive days. The starting time of deployments varied haphazardly among trials, but was matched between urban and rural beaches within a trial. To ensure that both diurnal and nocturnal scavengers could be detected if present, we deployed carrion during the day (between 10 am and $3 \mathrm{pm}$ ) in trials 1,2 and 4, and just before sunset (5 pm) in trials 3 and 5. The three daytime deployments were 11 and 26 days apart, and the sunset deployments were 14 days apart. To ascertain that our deployments did not lead to learned attraction to camera locations of the scavengers, we fit linear mixed-effects models to investigate correlations with time to scavenging (in minutes) for daytime and sunset deployments separately. For sunset deployments, Trial $(p=0.595)$, Urbanisation $(p=0.161)$ and their interaction $(p=0.297)$ were all nonsignificant, indicating that there was no discernible learning effect at night. For daytime deployments, time to scavenging was significantly faster for Trial 2 than for either Trial $1(\mathrm{p}=$ $0.007)$ or Trial $4(p=0.038)$, although again the Urbanisation effect $(p=0.309)$ and the interaction between Trial and Urbanisation $(p=0.824)$ were non-significant. These results suggest that there is no evidence that scavengers systematically improved their ability to detect the deployed carcasses.

In each camera deployment, one fish carcass $(383 \pm 113 \mathrm{~g})$ was placed on the beach near the dunes. Flathead grey mullet, Mugil cephalus, was used as carrion because this species is commonly found in the surf-zone of beaches worldwide, and as carrion is scavenged by several 
species (Schlacher et al., 2013). Each fish was monitored for $24 \mathrm{~h}$ with a digital Passive Infrared (PIR), motion-triggered camera (ScoutGuard SG560Z-8M). This technique is commonly used to assess the occurrence and nature of scavenging at carcasses (Hamel et al., 2012). Each camera was set to take three consecutive pictures upon detection of movement, with a reset period of 7 seconds in between trigger events. The cameras took 136,420 pictures in total, ranging from 15 to 5508 images per deployment. Large numbers of images were not necessarily the result of large numbers of scavengers because other moving objects also triggered cameras (e.g. vegetation moved by the wind, walkers, cars, etc.). We elected to expose carrion for a standardised period of $24 \mathrm{~h}$ chiefly because urban beaches are periodically groomed and longer exposures would thus have introduced the possibility of positive bias (i.e. carcass removal by beach cleaners) in estimates of carcass consumption on urban beaches. No evidence of grooming was observed on the day of carcass placement during the experiments. We report all results against this standardised exposure time.

Animals were recorded as scavengers when they were detected with the fish in their mouth, with their mouth touching the fish, or when they appeared next to the fish in an image and the fish was missing from the next image.

\subsection{Data analysis}

The species richness of the scavenger guild was compared between urban and rural areas using sample-based species-accumulation curves, as determined from random permutations of the data, or subsampling without replacement (Gotelli and Colwell, 2001). In estimating species richness, the number of scavenger species (as defined above) recorded at each carrion deployment was recorded, regardless of the number of individuals present to avoid overrepresentation of species that naturally scavenge in groups rather than individually. Species composition by beach and trial was then assessed by aggregating scavenger species incidences across all sites within individual beaches for each trial. Non-metric multidimensional scaling (nMDS; based on Bray-Curtis resemblance matrices calculated from untransformed data of aggregated species incidence per beach and trial) was used to visualize differences in scavenger species composition among beaches and trials. To test whether the structure of the scavenger guild differed between urban and rural beaches (the main test of interest according to our hypothesis), we used a simple additive Permutational Multivariate Analysis of Variance (PERMANOVA) to fit a linear model to Bray Curtis distance matrices (Anderson, 2001; Oksanen et al., 2012). Three trials from the urban beach 'Alexandra Headland' recorded zero scavengers and therefore had to be omitted from PERMANOVA, making the test a conservative one (i.e., differences between urban and rural scavenger community composition are larger than suggested by PERMANOVA).

SIMPER analysis (in PRIMER) was used to highlight which species contributed most to the dissimilarity in community composition between urban and rural beaches. Because violations of mean-variance assumptions may confound dispersion and location effects (Warton et al., 2012), we supplemented SIMPER analysis with Poisson mixed-effects linear models (Bolker et al., 
2009) for each species separately to test for species-level effects of urbanisation. In each case, we modelled the number of times a scavenger species was observed as a function of urbanisation (fixed effect), beach (random effect, to account for repeated sampling at specific beaches nested within levels of urbanisation), and individual observation (to account for overdispersion of the Poisson regression). Significance was assessed on the basis of a likelihood-ratio test of the fit of model containing the urbanisation factor relative that for the model without the urbanisation factor (Bolker et al., 2009; Zuur et al., 2007).

The likelihood of a carcass being removed by scavengers within $24 \mathrm{~h}$ (binary outcome) was modelled using a logistic mixed-effects model with binomial error structure. Our full model included level of urbanisation as a fixed effect having two levels (urban and rural), with trial and beach as random effects because their levels were selections from larger pools to which we wish to generalise our results. Generalized linear mixed-effects modeling is powerful not only because it models data using a realistic error structure, but also because it accommodates missing values (cameras were not recovered on six occasions), and it specifically acknowledges the nested structure of the survey design, thereby accounting for the fact that we repeatedly revisited the same sites on the same beaches (Bolker et al., 2009; Zuur et al., 2007). The full model was simplified following the suggestions of Zuur et al. (2007) and Bolker (2009), namely: starting with the full model and searching for optimal model structure by sequentially dropping random and then fixed effects. Improved model fit is indicated by a smaller Akaike information criterion (AIC), a smaller Bayesian information criterion (BIC) and a strongly non-significant likelihoodratio test, which indicates that the fit of the simpler model did not cause a significant deterioration in fit in terms of deviance ( -2 times the log-likelihood). Because the likelihood-ratio test can be biased for fixed effects (Bolker et al., 2009), we verified the results in this instance with a Wald $\chi^{2}$ test.

\section{Results}

Urbanisation substantially changed the community structure of the scavenger guild and the probability of carrion removal over a $24 \mathrm{~h}$ exposure period. Although species richness was comparable between urban and rural beaches ( $n=6$ for both levels of urbanisation), the composition of the scavenger guild was significantly different (PERMANOVA, Urbanisation effect: $F_{1,21}=20.701, p=0.001$ ).

The large structural separation of the scavenger guild between rural and urban beaches was mainly due to raptors (brahminy kite, Haliastur indus, and whistling kite, $H$. sphenurus) being the dominant scavenger species on rural beaches, whereas feral mammals (rats, Rattus spp.), were more common on urban beaches (Table 1, Figure 2). The only species detected to consume fish carcasses on both rural and urban beaches were red foxes (Vulpes vulpes) and Torresian crows (Corvus orro). These species occurred at comparable frequencies on both beach types, but accounted for a signifiantly larger proportion of necromass removal on urban shores. Scavengers remained unidentified when the fish carcass was no longer present but no scavenger was captured 
on the images. This most likely results from raptors lifting carrion off the beach faster than the trigger delay of the cameras.

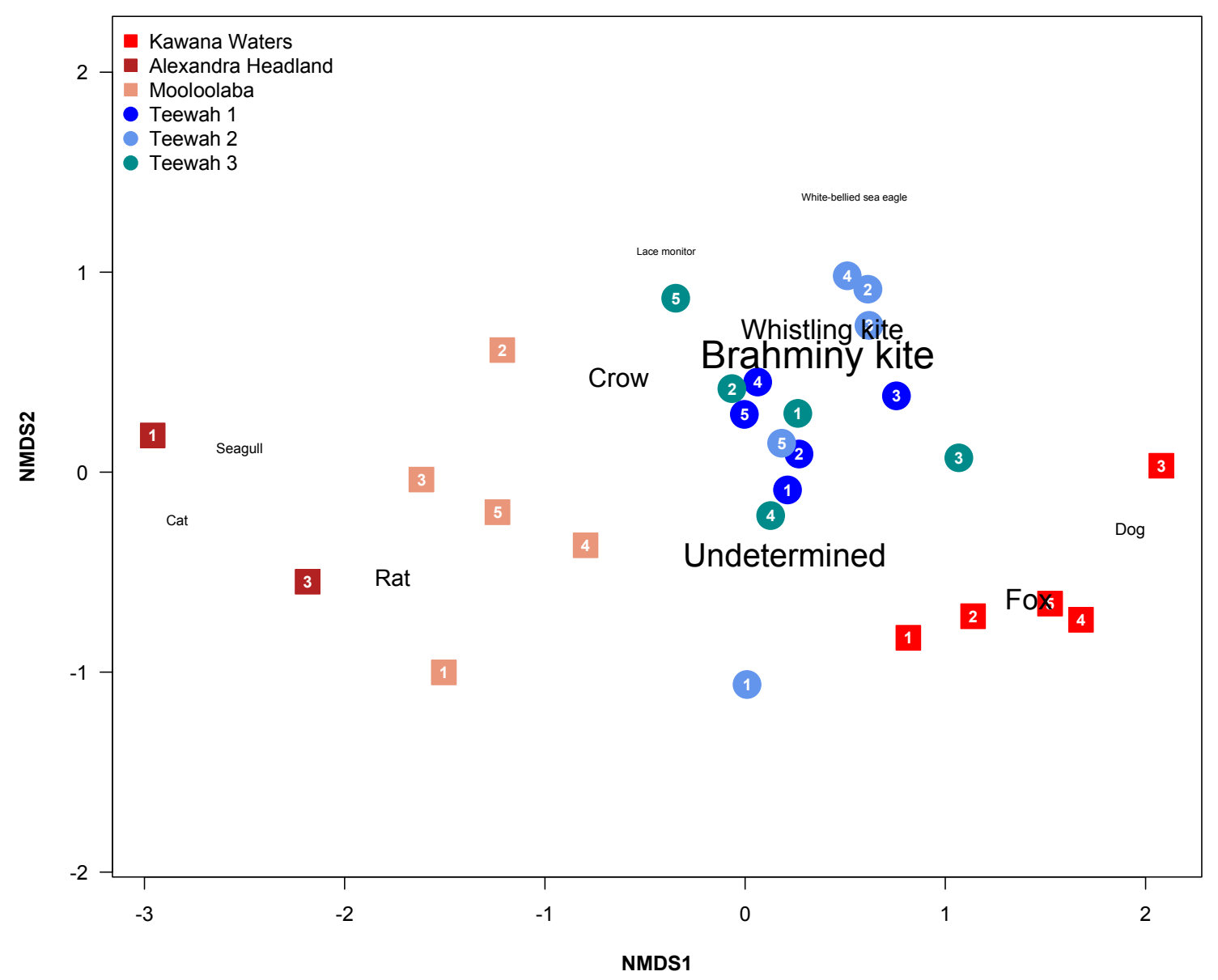

Figure 2. nMDS biplot (based on Bray-Curtis resemblance from untransformed data) of scavenger species composition at experimental deployments of carrion on urban (squares in shades of red) and rural (circles in shades of blue) beaches (numbers represent different trials). Font size of scavenger names is scaled to reflect the relative frequency of observation for a species, and positioning of names reflects associations with the nMDS ordination. 
Table 1 The frequency of occurrence of scavenger species on urban and rural beaches, determined as the number of camera deployments in which a species was positively recorded consuming carrion. Species in the table are ordered according to their percentage contribution (based on SIMPER) to the dissimilarity in community composition between urban and rural beaches. 'Undetermined' denotes events where fish carcasses were removed from the beach but the actual scavenger species consuming the carrion was not captured by the camera, most likely a bird of prey swooping on fish carcasses and lifting them off the beach (Schlacher pers. obs.). '-' accounts for species that contributed less than $10 \%$ to the dissimilarity between urban and rural beaches. Mixed-effects model $\mathrm{p}$ values indicate the significance (according to a likelihood-ratio test) of urbanisation for Poisson generalized mixed-effects linear models of scavenging occurrences for each of the species, separately (see Methods).

\begin{tabular}{|c|c|c|c|c|}
\hline \multirow[b]{2}{*}{ Scavenger species } & \multicolumn{2}{|c|}{ Occurrence } & \multirow[b]{2}{*}{$\begin{array}{c}\% \text { contribution to } \\
\text { dissimilarity }\end{array}$} & \multirow[b]{2}{*}{$\begin{array}{l}\text { Mixed-effects } \\
\text { model p }\end{array}$} \\
\hline & $\begin{array}{l}\text { Urban } \\
(n=55)\end{array}$ & $\begin{array}{l}\text { Rural } \\
(n=59)\end{array}$ & & \\
\hline Brahminy kite & 0 & 33 & 36.7 & $<0.0001$ \\
\hline Undetermined & 3 & 15 & 15.0 & 0.0235 \\
\hline Whistling kite & 0 & 11 & 12.2 & 0.0002 \\
\hline Red fox & 10 & 3 & 10.8 & 0.8343 \\
\hline Torresian crow & 4 & 6 & 8.5 & 0.5809 \\
\hline Rat & 7 & 0 & 7.9 & 0.0262 \\
\hline Domestic dog & 4 & 0 & - & 0.3730 \\
\hline Domestic cat & 2 & 0 & - & 0.2100 \\
\hline Silver gull & 2 & 0 & - & 0.1386 \\
\hline White-bellied sea eagle & 0 & 1 & - & 0.5631 \\
\hline Lace monitor & 0 & 1 & - & 0.5631 \\
\hline
\end{tabular}

Most (64\%) of the fish carcasses that we had deployed on urban beaches remained uneaten after 24 hours: the few positive records of scavengers on urban beaches consisted mainly of red foxes and rats (Rattus spp.), complemented by Torresian crows, domestic dogs (Canis familiaris), domestic cats (Felis catus), and silver gulls (Chroicocephalus novaehollandiae) (Fig. 3). On urban beaches only foxes, and on three occasions domestic dogs, removed entire fish carcasses, while the other scavenger species only fed on small proportions of the fish $(<20 \%$ of the mass). The differences in scavenger guilds were closely related to the time of day at which scavenging occurred (Table 2). Scavenging guilds on urban beaches were dominated by mammals that were mainly active at night, while rural scavengers were mostly avian species that foraged during the day. 

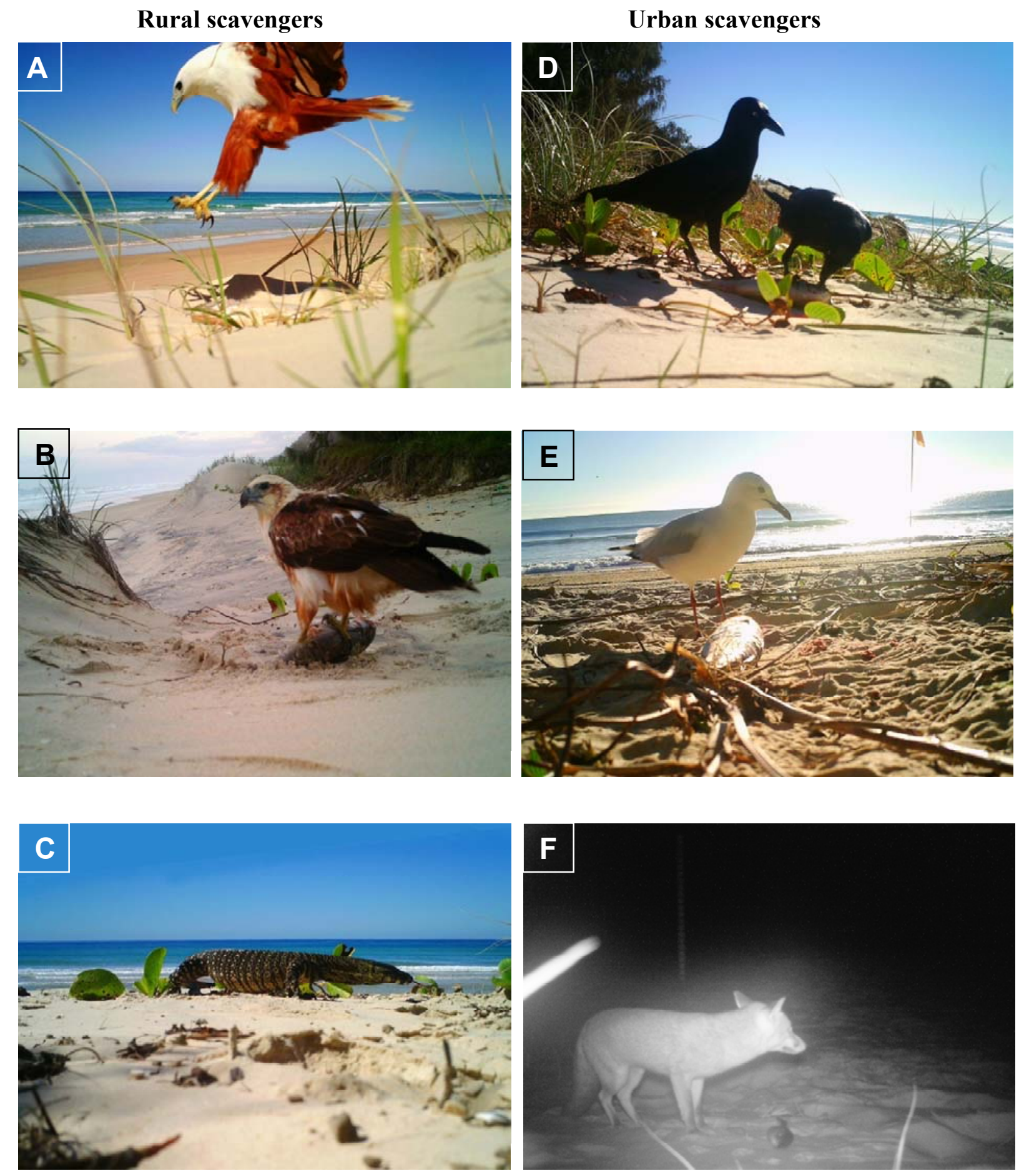

Figure 3. Examples of scavengers detected on rural beaches: A) brahminy kite (Haliastur indus), B) whistling kite (Haliastur sphenurus), C) lace monitor (Varanus varius), and urban beaches: D) Torresian crow (Corvus orro), E) silver gull (Chroicocephalus novaehollandiae), F) red fox (Vulpes vulpes). 
Species-accumulation curves for both rural and urban beaches converged on the six identified scavenger species, and although the curve is initially slightly steeper for rural than urban beaches, the asymptote is reached more quickly for urban than rural beaches (Figure 4). The curve for urban beaches plateaued earlier because the scavenging community of rural beaches contained two singletons (lace monitors Varanus varius and white-bellied sea eagles Haliaeetus leucogaster), whereas urban beaches had none, suggesting that the structure of the urban scavenging community may have been slightly better quantified by our survey methods than that of the rural beaches.
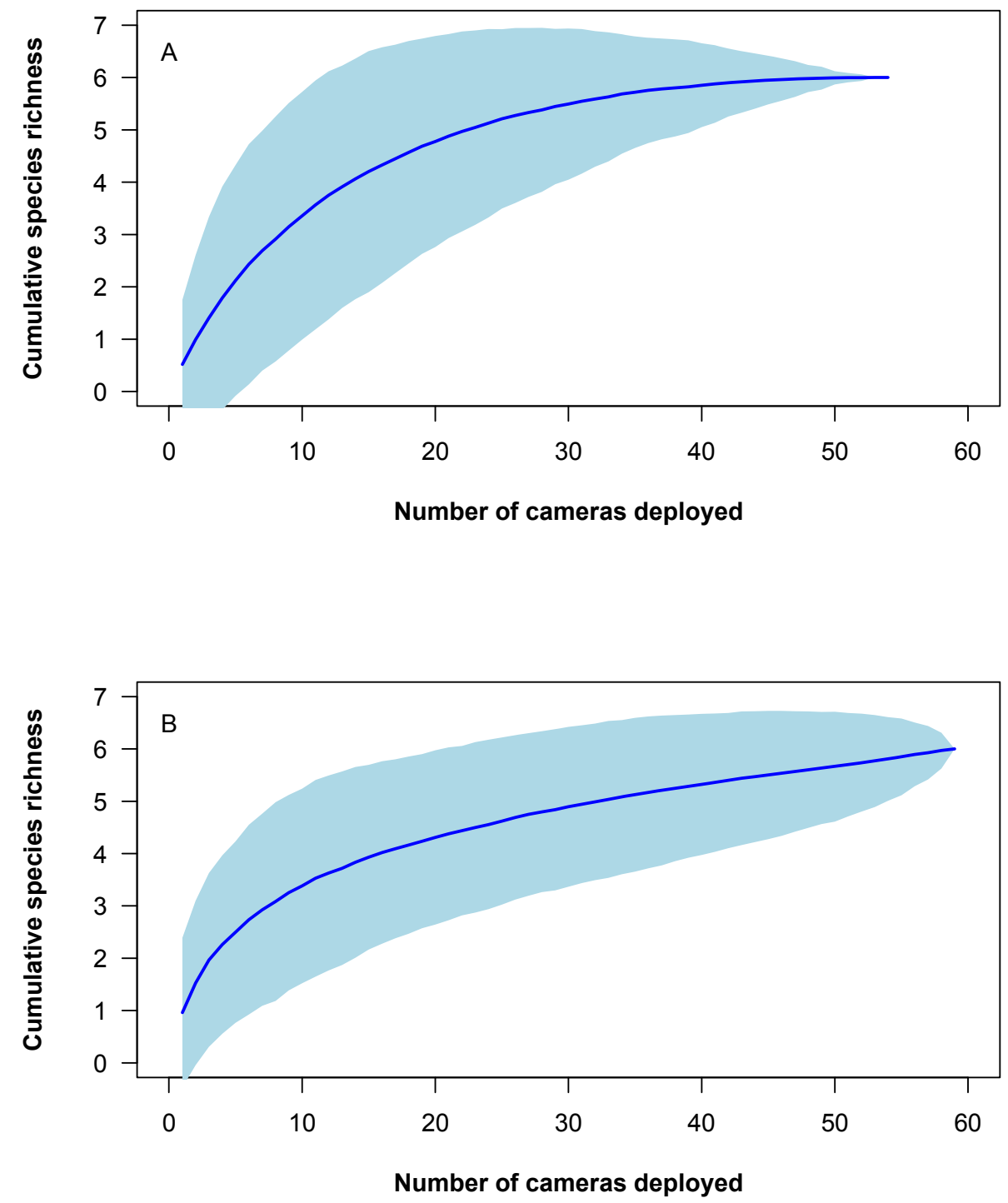

Figure 4. Species-accumulation curves for scavenger communities observed at experimental carrion deployments at A) urban, and B) rural beaches. Blue areas represent the standard deviations as determined from 1000 random permutations of the data (subsampling without replacement). 
Table 2. Comparison of the total number of individual avian and mammalian scavengers, recorded during either day or night time with motion-triggered cameras on urban and rural beaches. The presence of avian and mammalian scavengers is closely related to the time of day when scavenging occurred.

\begin{tabular}{c|ccc|ccc|} 
& \multicolumn{3}{|c|}{ Birds } & \multicolumn{3}{c}{ Mammals } \\
& Day & Night & Total & Day & Night & Total \\
\hline Urban & 3 & 3 & 6 & 3 & 19 & 22 \\
Rural & 51 & 0 & 51 & 0 & 3 & 3 \\
\hline & 54 & 3 & 57 & 3 & 22 & 25
\end{tabular}

Scavenging of carrion from rural beaches was rapid and intense: $98 \%$ of experimentally-deployed fish carcasses were removed by scavengers within 24 hours. Initial inspection of the logistic mixed-effects model indicated that the random effect for Trial was non-significant $(2 \times \Delta$ Loglikelihood $=0.03, \mathrm{df}=1, \mathrm{p}=0.863)$, but that the random effect for Beach was significant $(2 \times$ $\Delta$ Log-likelihood $=25.563, \mathrm{df}=1, \mathrm{p}<0.0001)$. The fixed effect for Urbanisation was strongly significant $\left(2 \times \Delta\right.$ Log-likelihood $=6.5877, \mathrm{df}=1, \mathrm{p}=0.01 ;$ Wald $\left.\chi^{2}=7.4515, \mathrm{df}=1, \mathrm{p}=0.006\right)$. Estimates from the final model confirm that the likelihood of a carcass being removed by scavengers from rural beaches within 24 hours was close to $100 \%$ (Figure 5). By contrast, the likelihood of a carcass being removed from an urban beach within 24 hours is much lower $(22 \%$ on average, but with a wide confidence interval), which is no different from even odds.

The time of deployment affected the time lag between deployment and occurrence of a scavenger at a carcass. Daytime deployments led to quick detection by diurnally active avian species on rural beaches: $86 \%$ of all fish carcasses that were deployed during the day were detected by scavengers within $4 \mathrm{~h}$ of placement on the beach (mean \pm s.d. time to first scavenger: 3:02 \pm 5:52 h). By contrast, when carrion was placed on rural beaches close to sunset, scavengers were much slower to detect carcasses: $55 \%$ of these carcasses remained after $12 \mathrm{~h}$, and many of these were removed the next day by diurnal scavengers (mean \pm s.d. time to first scavenger: 10:03 \pm 8:18 h). Arrival of scavengers at an experimental carcass was more protracted on urban beaches, both for diurnal and nocturnal scavengers. On urban beaches, the mean time ( \pm s.d.) to detection for daytime deployments was 7:32 ( \pm 4:59) $\mathrm{h}$. The frequent occurrence of foxes, mostly crepuscular and nocturnal foragers, on urban beaches resulted in relatively quick detection times (4:06 4:41 h) in deployments done close to sunset. 


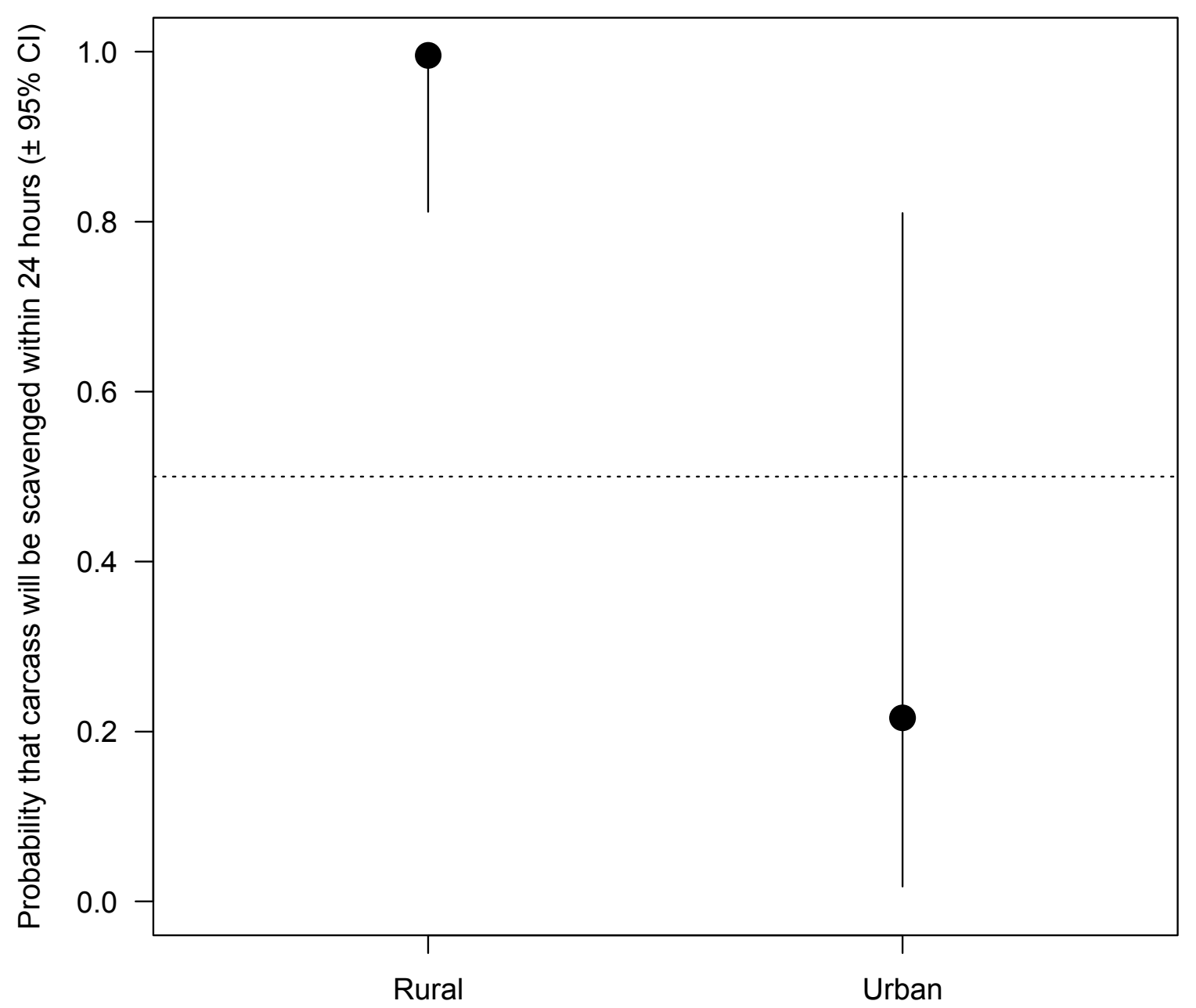

Degree of urbanisation

Figure 5. Probability (calculated from a logistic mixed-effects model with binomial error structure) that a fish carcass will be removed within 24 hours from rural and urban beaches. The dashed line represents the 50:50 chance that a carrion item is removed by scavengers within the observation period of $24 \mathrm{~h}$.

\section{Discussion}

Urbanisation significantly altered scavenging patterns on sandy beaches of southeast Queensland, Australia: urban beaches supported a suite of scavengers, including non-native and feral 
mammals, which removed significantly less carrion within 24 hours than did the raptordominated scavenger communities on rural beaches. Although our study is the first to compare removal of marine carrion by terrestrial and avian vertebrate scavengers simultaneously on urban and rural beaches, our results correspond to those from a previous study of scavenging rates in six tropical habitats along an urbanisation gradient, which showed longer detection times and lower scavenging rates by insects on dead invertebrates in more urbanised areas (Tan and Corlett, 2012). This suggests a generalisation in the ways in which changes in land-use, and especially urbanisation, can affect key ecological processes.

The consequences of such changes to fundamental trophic processes in coastal food-web structure could be profound, and should be taken into consideration by coastal planners and managers. A significant and accelerating threat being faced by the narrow strip of coast that comprises sandy beaches is coastal squeeze (Schlacher et al., 2008). This phenomenon is caused by rising sea levels, which combine with expanding urbanisation to trap and slowly drown beaches. Trends in sea-level rise are impossible to alter in the short to medium term, so to conserve beaches, coastal managers can only regulate urban and peri-urban development. Planning the type and spatial location of development that might irreversibly alter habitat dimensions, habitat connectivity, or quality, requires an understanding of how changes in coastal habitats affect critical ecosystem services. Management of beaches has traditionally focused on maintaining recreational opportunities in urban settings, with scant regard to conserving ecological processes in urban planning of sandy shorelines (Schlacher et al., 2007; Schlacher et al., 2006). The lack of robust metrics by which to assess the effects of human interventions on beach systems has been considered to impede more ecologically-focused approaches to beach management (James, 2000; Micallef and Williams, 2002; Schlacher et al., 2006). Our metric of scavenging captures an essential mechanism of nutrient and organic matter transfer in ecosystems at the land-ocean interface that has potential in environmental monitoring and planning applications. For example, our key finding of the importance of large avian scavengers in the systems studied has implications for conserving and providing critical nesting and foraging sites for these threatened vertebrates.

Dominant scavenger species in rural areas (brahminy and whistling kite) were not detected by us in urban areas. Clergeau et al. (2006) showed that avian species composition in urbanised areas is generally simplified, with a paucity of habitat specialists. Many species of raptor are highly sensitive to urbanisation, which has led to a dramatic decrease in numbers of some raptor species worldwide (Berry et al., 1998; Eduardo et al., 2007). Furthermore, the scavenging raptors we report are predominantly diurnal feeders, and their absence from urban beaches might be related to human presence and disturbance during the day. Larger bird species exhibit an earlier response to human disturbances, and move further away after being disturbed (Blumstein et al., 2005; Weston et al., 2012). The avian scavengers we recorded on urban beaches (e.g., gulls and crows) tend to be commensal with, or at least highly tolerant, of human presence (Weston et al., 2012). The fact that we detected no significant scavenging activity of raptors on urban beaches suggests 
that densities are too low to be a major influence on carrion processing in urban areas. This highlights the impact of urban development on beach and dune-dependent species that occur naturally in less disturbed areas (Meager et al., 2012). Ironically, although we show that coastal development alters the wildlife species occurring on beaches, many coastal residents desire wildlife on beaches (Maguire et al., 2011).

In addition to altered scavenger guilds, urbanisation also affected the amount of carrion that was removed within 24 hours from sandy beaches. All but one of the deployed fish carcasses were removed within 24 hours from the beaches in the rural area, compared to only 20 out of 55 on urban beaches. Removal rate is partly influenced by the composition of scavenger species (Bodkin and Jameson, 1991). Large raptors and foxes tend to consume fish carcasses completely, or at least to remove them from the beach, in contrast to smaller mammalian and avian scavengers that dominated on the urban beaches. The raptors reported in our study search for their food with an energetically efficient soaring locomotion (Ruxton and Houston, 2004), resulting in a much quicker and larger removal rate of carrion compared with mammalian scavengers. It is plausible that some fish carcasses might eventually have been removed by scavengers had we left them on the beach beyond 24 hours, for example by scavengers that mainly use olfactory cues to detect carrion, or by occasional forays into urban settings by primarily rural raptors. However, urban beaches tend to be regularly groomed by local councils, so such scavengers are unlikely to contribute significantly to coastal energy flows. Therefore, although we acknowledge that deliberate removal of the fish carcasses after 24 hours does not reveal the ultimate fate of carrion, our results clearly show that urbanisation has knock-on impacts on the scavenging process: by altering the species composition of the scavenger guild, urbanisation reduces the rate of carrion consumption, which might have broader impacts throughout coastal food webs.

The rapid and intense removal of the fish carcasses on rural beaches equals scavenging rates in reported for some other ecosystems. Below sea level, fish removed all carrion deposited on coral reefs within 24 hours (Rassweiler and Rassweiler, 2011). In terrestrial systems, removal rates of $>95 \%$ within 3 days have been observed in tropical forests (Houston, 1986) and agricultural fields (Peterson et al., 2001), where raptors such as vultures, bald eagles and harriers dominated the scavenging guild. Despite the significant and substantial effects of urbanisation on scavengers and scavenging found by us, carrion removal by vertebrate scavengers continues on urbanised beaches (i.e. $36 \%$ of the carrion was removed within $24 \mathrm{hrs}$ ). This demonstrates the pervasive ecological role of scavenging even in highly modified systems (Wilson and Wolkovich, 2011). Importantly, the disruption of native scavenging assemblages seems to assist generalist vertebrate pest species, which have been reported to prey on wildlife, such as beach-nesting birds (Maguire et al., 2010). Furthermore, the presence of introduced species (foxes, feral dogs and cats), that have been repeatedly demonstrated to be serious threats to native wildlife (Loss et al., 2013; Short and Smith, 1994), compounds the negative effects of urbanisation on coastal ecosystems. 
Food-web subsidies are critical to the functioning of sandy beaches (Schlacher et al., 2008). The consumption of fish carcasses by terrestrial scavengers forms an important conduit by which marine nutrients are translocated into terrestrial systems (Polis et al., 2004). Although some scavengers consume carrion completely, remains of the fish carcasses can be consumed by species of lower trophic position such as ghost crabs (Wolcott, 1978) or wolf spiders (Morse, 1997). In this way, marine subsidies can propagate across multiple levels in coastal food webs (Spiller et al., 2010). It is clear from our research that these processes differ between areas with different levels of human development. In rural areas, where avian scavengers dominate the transfer of marine carrion to coastal food webs, marine subsidies are likely to be transferred over much larger distances compared with urban areas with small mammalian scavengers. Further research is needed to investigate the quantitative contribution of marine subsidies and the distance over which these are transferred into terrestrial systems.

In conclusion, our study shows that human transformation of coastal habitats has a substantial impact on the composition of the scavenging guild, and consequently on the efficiency with which marine carrion is removed from sandy beaches. As an increasing number of people live in expanding urban and peri-urban conurbations, it is important to develop a more robust understanding of how trends in human coastal demography and land-use affect key ecological processes and structures. 


\section{References}

Anderson, M. J., 2001, A new method for non-parametric multivariate analysis of variance, Austral Ecology 26(1):32-46.

Barton, P. S., Cunningham, S. A., Lindenmayer, D. B., Manning, A. D., 2013, The role of carrion in maintaining biodiversity and ecological processes in terrestrial ecosystems, Oecologia 171(4):761-72.

Beasley, J. C., Olson, Z. H., DeVault, T. L., 2012, Carrion cycling in food webs: comparisons among terrestrial and marine ecosystems, Oikos 121(7):1021-1026.

Berry, M. E., Bock, C. E., Haire, S. L., 1998, Abundance of diurnal raptors on open space grasslands in an urbanized landscape, Condor:601-608.

Blumstein, D. T., Fernandez-Juricic, E., Zollner, P. A., Garity, S. C., 2005, Inter-specific variation in avian responses to human disturbance, Journal of Applied Ecology 42(5):943-953.

Bodkin, J. L., Jameson, R. J., 1991, Patterns of seabird and marine mammal carcass deposition along the central California coast, 1980-1986, Canadian Journal of Zoology 69(5):1149-1155.

Bolker, B. M., Brooks, M. E., Clark, C. J., Geange, S. W., Poulsen, J. R., Stevens, M. H. H., White, J.-S. S., 2009, Generalized linear mixed models: a practical guide for ecology and evolution, Trends in Ecology \& Evolution 24(3):127-135.

Clergeau, P., Croci, S., Jokimäki, J., Kaisanlahti-Jokimäki, M. L., Dinetti, M., 2006, Avifauna homogenisation by urbanisation: analysis at different European latitudes, Biological Conservation 127(3):336-344.

DeVault, T. L., Olson, Z. H., Beasley, J. C., Rhodes, O. E., 2011, Mesopredators dominate competition for carrion in an agricultural landscape, Basic and Applied Ecology 12(3):268274.

DeVault, T. L., Rhodes, O. E., Shivik, J. A., 2003, Scavenging by vertebrates: behavioral, ecological, and evolutionary perspectives on an important energy transfer pathway in terrestrial ecosystems, Oikos 102(2):225-234.

Duxbury, J., Dickinson, S., 2007, Principles for sustainable governance of the coastal zone: in the context of coastal disasters, Ecological Economics 63(2-3):319-330.

Eduardo, C., Carvalho, A., Marini, M. A. N., 2007, Distribution patterns of diurnal raptors in open and forested habitats in south-eastern Brazil and the effects of urbanization, Bird Conservation International 17(04):367-380.

Gotelli, N. J., Colwell, R. K., 2001, Quantifying biodiversity: procedures and pitfalls in the measurement and comparison of species richness, Ecology Letters 4(4):379-391.

Gurran, N., 2008, The turning tide: amenity migration in coastal Australia, International planning studies 13(4):391-414.

Hamel, S., Killengreen, S. T., Henden, J. A., Eide, N. E., Roed $\square$ Eriksen, L., Ims, R. A., Yoccoz, N. G., 2012, Towards good practice guidance in using camera $\square$ traps in ecology: influence of sampling design on validity of ecological inferences, Methods in Ecology and Evolution.

Houston, D. C., 1986, Scavenging efficiency of turkey vultures in tropical forest, Condor 88:318323.

James, R. J., 2000, From beaches to beach environments: linking the ecology, human-use and management of beaches in Australia, Ocean \& Coastal Management 43(6):495-514.

Longhurst, R., 1997, Mooloolaba Surf Lifesaving Club: Our club our story 1922-1997, Mooloolaba, QLD: The Mooloolaba Surf Lifesaving Club. 
Loss, S. R., Will, T., Marra, P. P., 2013, The impact of free-ranging domestic cats on wildlife of the United States, Nature Communications 4.

Lotze, H. K., Lenihan, H. S., Bourque, B. J., Bradbury, R. H., Cooke, R. G., Kay, M. C., Kidwell, S. M., Kirby, M. X., Peterson, C. H., Jackson, J. B. C., 2006, Depletion, degradation, and recovery potential of estuaries and coastal seas, Science 312(5781):1806-1809.

Lucrezi, S., Schlacher, T. A., Walker, S., 2009, Monitoring human impacts on sandy shore ecosystems: a test of ghost crabs (Ocypode spp.) as biological indicators on an urban beach, Environmental Monitoring and Assessment 152(1-4):413-424.

Maguire, G. S., Miller, K. K., Weston, M. A., Young, K., 2011, Being beside the seaside: beach use and preferences among coastal residents of south-eastern Australia, Ocean \& Coastal Management 54(10):781-788.

Maguire, G. S., Stojanovic, D., Weston, M. A., 2010, Conditioned taste aversion reduces fox depredation on model eggs on beaches, Wildlife research 36(8):702-708.

Martínez, M. L., Intralawan, A., Vázquez, G., Pérez-Maqueo, O., Sutton, P., Landgrave, R., 2007, The coasts of our world: ecological, economic and social importance, Ecological Economics 63(2-3):254-272.

McKinney, M. L., 2006, Urbanization as a major cause of biotic homogenization, Biological Conservation 127(3):247-260.

McLachlan, A., Brown, A. C., 2006, The ecology of sandy shores, Academic Press, Burlington, Massachusetts.

Meager, J. J., Schlacher, T. A., Nielsen, T., 2012, Humans alter habitat selection of birds on ocean-exposed sandy beaches, Diversity and Distributions 18(3):294-306.

Micallef, A., Williams, A., 2002, Theoretical strategy considerations for beach management, Ocean \& Coastal Management 45(4):261-275.

Morse, D. H., 1997, Distribution, movement, and activity patterns of an intertidal wolf spider Pardosa lapidicina population (Araneae, Lycosidae), Journal of Arachnology 25(1):1-10.

Noriega, R., Schlacher, T. A., Smeuninx, B., 2012, Reductions in ghost crab populations reflect urbanization of beaches and dunes, Journal of Coastal Research 28(1):123-131.

Ogada, D., Torchin, M., Kinnaird, M., Ezenwa, V., 2012, Effects of Vulture Declines on Facultative Scavengers and Potential Implications for Mammalian Disease Transmission, Conservation Biology 26(3):453-460.

Oksanen, J., Blanchet, F. G., Kindt, R., Legendre, P., Minchin, P. R., O'Hara, R. B., Simpson, G. L., Solymos, P., Stevens, M. H. H., Wagner, H., 2012, vegan: Community Ecology Package. $\mathrm{R}$ package version 2.0-5, http://CRAN.R-project.org/package=vegan

Parmenter, R. R., MacMahon, J. A., 2009, Carrion decomposition and nutrient cycling in a semiarid shrub-steppe ecosystem, Ecological Monographs 79(4):637-661.

Peterson, C. A., Lee, S. L., Elliott, J. E., 2001, Scavenging of waterfowl carcasses by birds in agricultural fields of British Columbia, Journal of Field Ornithology 72(1):150-159.

Polis, G. A., Hurd, S. D., 1996, Linking marine and terrestrial food webs: allochthonous input from the ocean supports high secondary productivity on small islands and coastal land communities, American naturalist:396-423.

Polis, G. A., Sánchez-Piñero, F., Stapp, P. T., Anderson, W. B., Rose, M. D., 2004, Trophic flows from water to land: marine input affects food webs of islands and coastal ecosystems 
worldwide, in: Food webs at the landscape level (G. A. Polis, M. E. Power, G. R. Huxel, eds.), University of Chicago Press, Chicago, pp. 200-216.

Rassweiler, A., Rassweiler, T., 2011, Does rapid scavenging hide non-predation mortality in coral-reef communities?, Marine and Freshwater Research 62(5):510-515.

Rose, M. D., Polis, G. A., 1998, The distribution and abundance of coyotes: the effects of allochthonous food subsidies from the sea, Ecology 79(3):998-1007.

Ruxton, G. D., Houston, D. C., 2004, Obligate vertebrate scavengers must be large soaring fliers, Journal of theoretical biology 228(3):431-436.

Schlacher, T. A., Dugan, J., Schoeman, D. S., Lastra, M., Jones, A., Scapini, F., McLachlan, A., Defeo, O., 2007, Sandy beaches at the brink, Diversity and Distributions 13(5):556-560.

Schlacher, T. A., Schoeman, D. S., Dugan, J., Lastra, M., Jones, A., Scapini, F., McLachlan, A., 2008, Sandy beach ecosystems: key features, sampling issues, management challenges and climate change impacts, Marine Ecology 29:70-90.

Schlacher, T. A., Schoeman, D. S., Lastra, M., Jones, A., Dugan, J., Scapini, F., McLachlan, A., 2006, Neglected ecosystems bear the brunt of change, Ethology, Ecology \& Evolution 18(4):349-351.

Schlacher, T. A., Strydom, S., Connolly, R. M., 2013, Multiple scavengers respond rapidly to pulsed carrion resources at the land-ocean interface, Acta Oecologica 48:7-12.

Schlacher, T. A., Thompson, L., 2012, Beach recreation impacts benthic invertebrates on oceanexposed sandy shores, Biological Conservation 147(1):123-132.

Selva, N., Jędrzejewska, B., Jędrzejewski, W., Wajrak, A., 2005, Factors affecting carcass use by a guild of scavengers in European temperate woodland, Canadian Journal of Zoology 83(12):1590-1601.

Short, J., Smith, A., 1994, Mammal decline and recovery in Australia, Journal of Mammalogy 75(2):288-297.

Spiller, D. A., Piovia-Scott, J., Wright, A. N., Yang, L. H., Takimoto, G., Schoener, T. W., Iwata, T., 2010, Marine subsidies have multiple effects on coastal food webs, Ecology 91(5):14241434.

Tan, C. K. W., Corlett, R. T., 2012, Scavenging of dead invertebrates along an urbanisation gradient in Singapore, Insect Conservation and Diversity 5(2):138-145.

Warton, D. I., Wright, S. T., Wang, Y., 2012, Distance $\square$ based multivariate analyses confound location and dispersion effects, Methods in Ecology and Evolution 3(1):89-101.

Weston, M. A., Mcleod, E. M., Blumstein, D. T., Guay, P. J., 2012, A review of flight initiation distances and their application to managing disturbance to Australian birds, Emu 112:269286.

Wilson, E. E., Wolkovich, E. M., 2011, Scavenging: how carnivores and carrion structure communities, Trends in Ecology \& Evolution 26(3):129-135.

Wolcott, T. G., 1978, Ecological role of ghost crabs, Ocypode quadrata (Fabricius) on an ocean beach: scavengers or predators?, Journal of Experimental Marine Biology and Ecology 31(1):67-82.

Zuur, A. F., leno, E. N., Smith, G. M., 2007, Analysing Ecological Data, Springer, New York. 